\title{
Amount of Weight-Bearing During Tilt Table Inclination, With Neutral and Unilateral Knee Flexion Postures
}

\author{
Jung Hyun Yang, MD${ }^{1}$, Tae Wan Kim, MD${ }^{1}$, Sang Hun Kim, $\mathrm{MD}^{1}$, Byeong Ju Lee, $\mathrm{MD}^{1}$, \\ Jin A Yoon, $\mathrm{MD}^{1}$, Nam Hoon Moon, $\mathrm{MD}^{2}$, Myung Jun Shin, $\mathrm{MD}^{1}$, Yong Beom Shin, $\mathrm{MD}^{1}$ \\ Departments of ${ }^{1}$ Rehabilitation Medicine and ${ }^{2}$ Orthopaedic Surgery, Pusan National University Hospital, \\ Pusan National University School of Medicine, Busan, Korea
}

Objective To analyze the amount of weight-bearing during tilt table increments, with a review of neutral and unilateral knee flexion postures.

Methods There were 17 healthy participants enrolled in this study. The subjects were tilted from $10^{\circ}$ to $90^{\circ}$, and their body weight was measured at each $10^{\circ}$ increment. In the first test, both plantar pressures, with the subjects in neutral posture, were recorded. During the second and third tests, the angle of inclination was thus recorded and increased, with the subjects in unilateral knee flexion posture; flexion was maintained at $25^{\circ}$ by attaching a cylindrical support to the tilt table at the level of the popliteal fossa.

Results The study was divided into two types of postures: neutral and unilateral knee flexion. The percentage of body weight (\%BW) between each leg during neutral posture was noted as not being statistically significant. The $\% \mathrm{BW}$ of one side during tilt table inclination was significantly different between the two postures at $10^{\circ}$ to $80^{\circ}(\mathrm{p}<0.05)$. The weight during unilateral knee flexion posture was lower as analyzed, regardless of tilt table inclination compared with that in neutral posture. We note that fifty percent of the ratio of \%BW was noted at $33.12^{\circ}$ and $38.76^{\circ}$ in neutral and flexion postures, respectively.

Conclusion The unilateral knee flexion could induce the effect of decreased body weight compared with nonflexion side. The results of this study will help in setting a safe and quantitative percentage of weight-bearing on the lower extremity during tilt training.

Keywords Weight-bearing, Lower extremity, Fracture, Orthopedics, Rehabilitation

Received March 22, 2017; Accepted August 7, 2017

Corresponding author: Myung Jun Shin

Department of Rehabilitation Medicine, Pusan National University Hospital, Pusan National University School of Medicine, 179 Gudeok-ro, Seo-gu, Busan 49241, Korea. Tel: +82-51-240-7485, Fax: +82-51-247-7485, E-mail: drshinmj@gmail.com

ORCID: Jung Hyun Yang (http://orcid.org/0000-0002-8480-2187); Tae Wan Kim (http://orcid.org/0000-0002-5418-9406); Sang Hun Kim (http://orcid. org/0000-0003-4849-5228); Byeong Ju Lee (http://orcid.org/0000-0002-7250-8909); Jin A Yoon (http://orcid.org/0000-0001-5762-0559); Nam Hoon Moon (http://orcid.org/0000-0001-9975-0992); Myung Jun Shin (http://orcid.org/0000-0003-4010-0383); Yong Beom Shin (http://orcid.org/00000001-5026-1696).

() This is an open-access article distributed under the terms of the Creative Commons Attribution Non-Commercial License (http://creativecommons.org/ licenses/by-nc/4.0) which permits unrestricted noncommercial use, distribution, and reproduction in any medium, provided the original work is properly cited. Copyright $\odot 2018$ by Korean Academy of Rehabilitation Medicine 


\section{INTRODUCTION}

The incidence of lower extremity fractures has increased due to the increasing rates of traumatic injuries [1]. After an injury, the patient has to remain on bed rest for a certain period depending on type of fracture and operation method. Traditionally, once the bone remodeling has progressed, a gradual increase in lower-leg weight-bearing is needed to optimize fracture healing $[2,3]$. If weight-bearing is not performed, chronic complications, including joint contracture, muscle atrophy, gait disturbance, and osteoporosis, may result as a complication for the patient after an injury of this type.

To illustrate, it is important to understand that weightbearing can be divided into five types: non-weight-bearing, toe-touch weight-bearing, partial weight-bearing (PWB), weight-bearing-as-tolerated (WBAT), and full weight-bearing (FWB) $[4,5]$. Although a weight-bearing procedure after surgery is performed using the abovementioned sequence, doctors who prescribe rehabilitation therapy often do not know how much weight is applied on the injured leg during rehabilitation $[2,6,7]$. Therefore, the physical therapist checks the patient's pain level and proceeds with the next weight-bearing step using parallel bars or walker [2]. Although the need for accurate weight-bearing measures has been discussed previously, there are currently no quantitative weightbearing strategy system to date, because of the difficulty in measuring it objectively [6], and depending on the surgical site and, method, general condition of the patient, skin condition of the surgical site, and level of pain the weight-bearing may need to be adjusted for a patient on an individual basis [2].

The process of tilt table standing is an accessible weightbearing method for patients with musculoskeletal disorders as well as brain damage and spinal cord injury to be reviewed and analyzed $[8,9]$. This passive standing serves not only to increase weight-bearing, but also to help prevent joint contracture, muscle atrophy, and osteoporosis. In patients with lower extremity injury, the degree of PWB can be adjusted by increasing the angle.

In previous studies, it has been shown that, patients who performed tilt table standing evaluated the percentage of body weight-bearing according to angle change with the patient in neutral posture and with both knees flexed [8-10]. We have noted that both the unilateral and bilateral injuries are observed in real clinical practice and the patients with bilateral injuries have different degrees of severity in each side. However, in contrast, there were no references that we decided to apply neutral posture on one knee and unilateral knee flexion on the other knee. Therefore, we affirm that the aim of this study was to analyze the amount of body weight during tilt table increments, with neutral and unilateral knee flexion posture in normal adults.

\section{MATERIALS AND METHODS}

\section{Subjects}

In this study, there were 17 healthy subjects ( 10 men and 7 women) who were recruited as volunteers. The participants comprised young adults with no medical history, such as the incidence of musculoskeletal or central/peripheral nervous system abnormality. The baseline demographic characteristics in this study were as follows: average age, $28.59 \pm 2.79$ years; height, $170.84 \pm 9.53$ $\mathrm{cm}$; body weight, $65.37 \pm 12.64 \mathrm{~kg}$, respectively. The subjects, were reviewed when wearing same simple clothes and barefooted, were positioned on the tilt table with anatomical neutral posture.

\section{Study procedure}

A tilt table and two simple digital weighing scales of 0.2$\mathrm{kg}$ unit with zero-point-adjustment function and result-

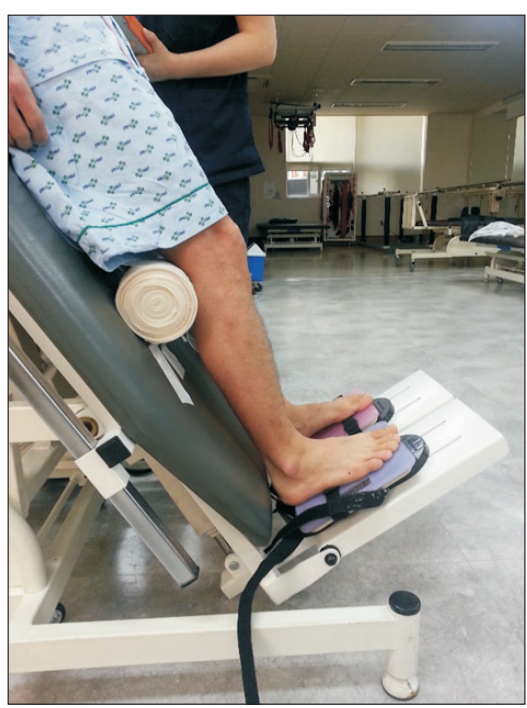

Fig. 1. Unilateral knee flexion posture during tilt table standing. 
fixing function were used as the basis of measurement during this study. Before the test, each subject's body weight was recorded and tilt table standing was started. As the table was tilted upward, each foot of a subject was placed, in parallel, on two simple digital weighing scales for 10 seconds. At that time, the subject was tilted, from $10^{\circ}$ to $90^{\circ}$, and his/her body weight was measured at each $10^{\circ}$ increments. The tilt table standing was performed three times per subject; with the first test noted as being performed with the subject in neutral posture, and in the second and third tests, both knees were alternately flexed (Fig. 1). To maintain a fixed flexion of $25^{\circ}$, a cylindrical support was attached to the tilt table at the level of the popliteal fossa. In this case, the cylindrical support was designed to be practical for the patient during weight bearing treatment and was made by wrapping five elastic bandages. As the tilt table inclined, we utilized the electronic scales which were placed side by side and the subject's gaze was directed toward the front, which minimizes compensatory actions such as center of gravity change when the participant looks elsewhere, and a strap was used on chest.

The test results were divided into two categories of postures: which were the neutral and flexion, with each type of posture having 34 results on both sides. The weight was measured in each $10^{\circ}$ in neutral and unilateral knee flexion postures, and then converted into measurable percentage. The percentage of body weight (\%BW) was thereafter calculated by dividing the patient's measured body weight on one leg by his or her full body weight at each $10^{\circ}$ of inclination. In this study, it was measured that while the tilt table rises at $10^{\circ}$ intervals, the weight-bearing ratio in neutral posture [(average \%BW during neutral posture) $/\left(\right.$ average $\% \mathrm{BW}$ at $90^{\circ}$ during neutral posture)] and flexion posture [(average \%BW during flexion posture)/(average $\% \mathrm{BW}$ at $90^{\circ}$ during neutral posture)] was measured. The ratios during neutral and flexion postures were measured as ratios 1 and 2, respectively.

\section{Statistical analysis}

In this study, all values are expressed as mean \pm standard deviation. The SPSS version 18.0 program (SPSS Inc., Chicago, IL, USA) was used for data analysis and processing. The mean and standard deviation of the variables between the two postures were calculated and compared using independent t-test analysis. We noted that during the timeframe of tilt table standing, with progressive $10^{\circ}$ to $90^{\circ}$ inclination at $10^{\circ}$ intervals, nine average $\% \mathrm{BW}$ results were obtained from the neutral and flexion postures, their differences between the two postures were compared. A linear regression was used at this time to estimate the $\% \mathrm{BW}$ from the angle of the tilt table.

Table 1. Average \%BW and ratio in neutral and unilateral knee flexion postures and their differences

\begin{tabular}{|c|c|c|c|c|c|}
\hline \multirow{2}{*}{ Angle of tilt $\theta\left(^{\circ}\right)$} & \multicolumn{2}{|c|}{ Neutral posture } & \multicolumn{2}{|c|}{ Flexion posture $\left(25^{\circ}\right)$} & \multirow{2}{*}{$\begin{array}{c}\text { Mean difference } \\
(\mathrm{N}-\mathrm{F})\end{array}$} \\
\hline & Average \%BW & Ratio $1(\mathbf{N})$ & Average \%BW & Ratio 2 (F) & \\
\hline 10 & $10.03 \pm 2.68$ & 20.21 & $8.51 \pm 3.00$ & 17.15 & $3.06^{*}$ \\
\hline 20 & $16.61 \pm 3.61$ & 33.47 & $14.12 \pm 4.00$ & 28.45 & $5.02 *$ \\
\hline 30 & $23.33 \pm 3.56$ & 47.01 & $19.70 \pm 5.02$ & 39.69 & $7.32^{*}$ \\
\hline 40 & $30.56 \pm 3.56$ & 61.58 & $27.70 \pm 5.27$ & 55.82 & $5.76^{*}$ \\
\hline 50 & $36.48 \pm 5.65$ & 73.50 & $32.57 \pm 5.92$ & 65.62 & $7.88^{*}$ \\
\hline 60 & $41.07 \pm 5.10$ & 82.76 & $37.70 \pm 6.84$ & 75.96 & $6.80^{*}$ \\
\hline 70 & $45.35 \pm 5.78$ & 91.37 & $41.97 \pm 6.36$ & 84.56 & $6.81^{*}$ \\
\hline 80 & $48.15 \pm 5.35$ & 97.02 & $44.78 \pm 5.73$ & 90.22 & $6.80^{*}$ \\
\hline 90 & $49.63 \pm 5.67$ & 100.00 & $46.83 \pm 6.08$ & 94.35 & 5.65 \\
\hline
\end{tabular}

Values are presented as mean \pm standard deviation.

\%BW, percentage of body weight; $\mathrm{N}$, neutral posture; F, knee flexion posture.

*Statistically significant difference of \%BW between the two postures.

Ratio $1=\overline{\text { Average \%BW on upright posture (49.63) }}$

Ratio $2=\frac{\text { Average \%BW on flexion posture }}{\text { Average \%BW on upright posture (49.63) }}$ 


\section{RESULTS}

In this study, there were a total of 17 subjects who were recruited. The average \%BW between each leg in neutral posture was not statistically significant as measured in the analysis. The \%BW at tilt table inclination was significantly different between the two postures at $10^{\circ}$ to $80^{\circ}$ $(\mathrm{p}<0.05)$ (Table 1). We noted that the weight in unilateral knee flexion posture was lower, regardless of the degrees of inclination of the tilt table compared with that in neutral posture. The average $\% \mathrm{BW}$ at $90^{\circ}$ was $49.63 \pm 5.67$. As a result, during tilt table inclination up to $10^{\circ}$ to $80^{\circ}$, the difference between ratios 1 and 2 was found between 3.06 and 7.88 and statistically significant. The angle with the largest difference was noted and measured at $50^{\circ}$. Fifty percent of the ratios 1 and 2 were noted at $33.12^{\circ}$ and $38.76^{\circ}$, respectively. The tilt table angle between $10 \%$ and $50 \%$ of $\%$ BW of two postures are listed in Table 2 .

Table 2. Tilt table angle between $10 \% \mathrm{BW}$ and $50 \% \mathrm{BW}$ in neutral and unilateral knee flexion postures

\begin{tabular}{ccc}
\hline \multirow{2}{*}{$\begin{array}{c}\text { Average } \\
\text { \%BW }\end{array}$} & \multicolumn{2}{c}{ Tilt table angle $\left({ }^{\circ}\right)$} \\
\cline { 2 - 3 } ) & Neutral posture & Flexion posture $\mathbf{( 2 5}^{\circ}$ ) \\
\hline $10 \%$ & 4.22 & 9.11 \\
\hline $20 \%$ & 23.73 & 29.12 \\
\hline $30 \%$ & 43.24 & 49.13 \\
$40 \%$ & 62.75 & 69.15 \\
\hline $50 \%$ & 82.25 & 89.16 \\
\hline
\end{tabular}

$\% \mathrm{BW}$, percentage of body weight.
The linear regression equations for estimating \% BW from the angle of the tilt table were $\% \mathrm{BW}=$ (angle of the tilt table) $\times 0.5126+7.8369, \mathrm{R}^{2}=0.9675$ in the neutral posture and $\% \mathrm{BW}=($ angle of the tilt table $) \times 0.4997+5.4478, \mathrm{R}^{2}=0.9762$ in the flexion posture (Fig. 2A and 2B, respectively).

\section{DISCUSSION}

The present study described the \%BW on the neutral and unilateral knee flexion postures, as reviewed and analyzed during tilt table inclination, while using simple digital weighing scales in normal young adults. The result of PWB in the two types of postures was noted as being significantly different at $10^{\circ}$ to $80^{\circ}$, and the exact weight loading for each angle in the tilt table was determined and analyzed.

We note in this study, that the surgical treatment after femoral fracture and osteoarthritis on the lower extremity, may increase the incidence of joint contracture resulting from bed rest, with unilateral lower limb flexion posture for pain relief or postoperative stabilization [11]. If there are cases of aggravated non-union fracture, delayed unions, infections, and skin defects in the injured area, the likelihood of a risk of incidence will increase in that case $[6,12]$. In this situation, if rehabilitation treatment is being pursued, and if the result is including weight-bearing on the affected side, once the procedure is started, the difference in weight-bearing will be different between the normal leg and the injured leg, which can then be determined. The study of Morgan et

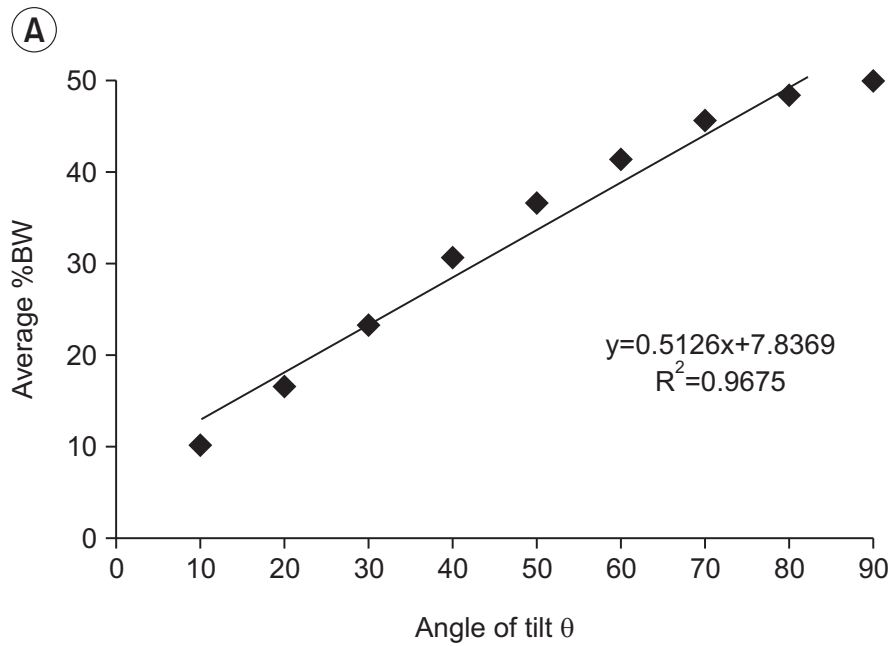

(B)

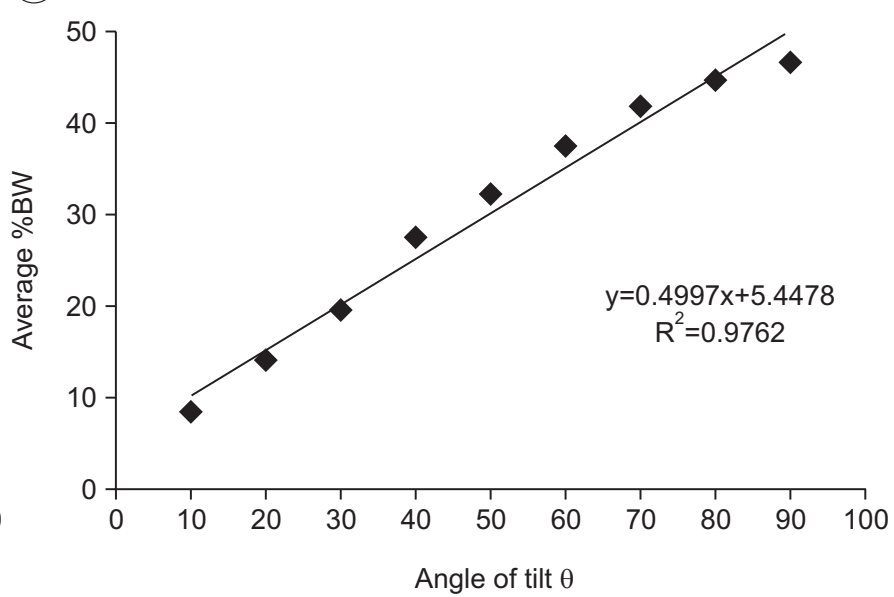

Fig. 2. Regression equation describing the relationship between percentage of body weight (\%BW) and tilt table angle in the neutral posture $(\mathrm{A})$ and the unilateral knee flexion $\left(25^{\circ}\right)$ posture (B). 
al. [9] reported \%BW decreases as the knee flexion angle increases due to increased quadriceps activity, which counteracts the flexion moment on flexed knees with the joint angle increase. However, as similarly noted in their paper, the flexion posture was performed on both knees simultaneously. Meanwhile, we noted and adjusted that in the present study utilized unilateral knee flexion, the results are characteristic and considered more similar to the condition of the patients in the former paper.

As we have mentioned earlier, the step of weight-bearing progresses gradually from toe-touch weight-bearing, PWB, WBAT, and FWB. When the patient begins to stand and walk, the direct FWB to the affected side may cause a burden of weight issues on the injury site of a patient. For this reason, there are the utilization of biofeedback systems and force plates which are used for objective evaluation $[6,8]$. However, during actual rehabilitation treatment, the exercise intensity is determined according to the patient's and physical therapist's perspectives, and the level of daily life performance, which may have a wide variety of results [13]. Hence, the quantitatively determination of the necessary amount of weight-bearing is significant and important, but it is difficult to accurately evaluate precisely in any case. There are many ways to increase weight-bearing, but this study performed a simple and inexpensive evaluation method using digital weighing scales and tilt table, which are widely used in treatment rooms. At present, the utilization of aqua therapy can be considered as PWB treatment 3 weeks after surgery in patients with unstable pelvic bone fracture, but not all hospitals are capable of carrying out this therapy because of lack of personnel or resources [14]. The use of effective quantitative weight-bearing during early rehabilitation therapy can make better health outcome for the patient, and help to prevent complications such as joint contracture and deep vein thrombosis while the patient manages recovery from an injury.

The trigonometrically determined value used to predict the degree of weight-bearing in the tilt table is greater than the measured \%BW. The study of Sheldon [10] found that it was effectively applied at over $10^{\circ}$. An approximate degree of weight-bearing in neutral posture can be expected during treatment in upright posture. We note that the difference between predicted value and measured value was $2.8 \%$ to $14.2 \%$ during tilt table inclination with more than $10^{\circ}$. This predicted value had a difference of
$0.74 \%$ to $4.43 \%$ when compared to the measured value of the present study. Although the two studies are similar in that the measured values are greater than the predicted values, we are able to assume that the increased weightbearing on non-flexion leg has led to greater measured value in the patients with unilateral knee flexion.

The noted friction force during tilt table inclination is known to increase with increasing body weight. However, this study did not measure friction force directly because we measured the ratio of body weight to tilt inclination. The friction force defined in general physics is independent of contact area and is known to be proportional to anti-gravity force as applied [15].

Our results also indicated that the angles corresponding to $50 \% \mathrm{BW}$ were different between the two postures which is in agreement with the results of the Morgan et al. [9], i.e., weight-bearing at the same angle decreases as knee flexion increases. With the utilization of linear regression equations (Fig. 2A, 2B), the doctor can determine the degree of PWB by adjusting the inclination of the tilt table. In like manner, the difference between ratios 1 and 2 was statistically significant during tilt table inclination between $10^{\circ}$ to $80^{\circ}$. We noted that during tilt table inclination, mean differences (N-F) at $30^{\circ}$ and $50^{\circ}$ are high relatively. However, this result was not clinically significant as a matter of fact, because only a small difference was observed along with the increase of \%BW during tilt inclination.

We understand that the present study has several limitations. First, the flexion angle was fixed at only one angle of $25^{\circ}$. The angle of $25^{\circ}$ was made by wrapping five elastic bandages together for the purpose of use in our study. It was designed to be easy and convenient to apply in real clinical settings. Second, it was noted that since the flexion posture used in this study was designed for normal subjects, it was thus unavoidably distributed the same level of strength to both sides, unlike the weight applied by actual patients with knee flexion posture due to injury. When standing with an asymmetric posture at different knee angles, the weight-bearing tends to be higher toward the normal lower limb than the injured side. This result showed that the same result not only for musculoskeletal patients but also for hemiplegic patients due to cerebrovascular disease $[16,17]$. Thus we have come to an understanding that further study in this area with the use of actual patients is necessary. 
Overall, we note that a unilateral knee flexion could induce a decrease in body weight ratio on that side of the patient, up to about $8 \%$, as compared with non-flexion side. In this study, we calculated and were able to obtain a quantitative value for increasing the weight-bearing in normal young adults with knee flexion posture, which allowed us to increase the weight-bearing to patients with a higher incidence of safely during treatment. The results of this study will be useful to increase the step of measuring the weight-bearing characteristics quantitatively reviewed, and to suggest that the patient will be able to walk afterwards as a result of following this procedure.

\section{CONFLICT OF INTEREST}

No potential conflict of interest relevant to this article was reported.

\section{REFERENCES}

1. Murphy DF, Connolly DA, Beynnon BD. Risk factors for lower extremity injury: a review of the literature. $\mathrm{Br}$ J Sports Med 2003;37:13-29.

2. Kubiak EN, Beebe MJ, North K, Hitchcock R, Potter MQ. Early weight bearing after lower extremity fractures in adults. J Am Acad Orthop Surg 2013;21:72738.

3. Meadows TH, Bronk JT, Chao YS, Kelly PJ. Effect of weight-bearing on healing of cortical defects in the canine tibia. J Bone Joint Surg Am 1990;72:1074-80.

4. Han TR, Bang MS, Jung SG. Rehabilitation medicine. Seoul: Koonja; 2014.

5. O'Young B, Young MA, Stiens SA. Physical medicine and rehabilitation secrets. 3rd ed. Philadelphia: Mosby/Elsevier; 2008.

6. Hustedt JW, Blizzard DJ, Baumgaertner MR, Leslie MP, Grauer JN. Current advances in training orthopaedic patients to comply with partial weight-bearing instructions. Yale J Biol Med 2012;85:119-25.
7. Vasarhelyi A, Baumert T, Fritsch C, Hopfenmüller W, Gradl G, Mittlmeier T. Partial weight bearing after surgery for fractures of the lower extremity: is it achievable? Gait Posture 2006;23:99-105.

8. Son SM, Lee JH, Cha YJ. Comparison of the plantar pressure distributions at different degrees of tilting: a preliminary report. J Phys Ther Sci 2014;26:401-3.

9. Morgan CL, Cullen GP, Stokes M, Swan AV. Effects of knee joint angle and tilt table incline on force distribution at the feet and supporting straps. Clin Rehabil 2003;17:871-8.

10. Sheldon MR. Comparison of two methods for calculating percent body weight on a tilt table. J Orthop Sports Phys Ther 1994;19:18-21.

11. Mavcic B, Antolic V. Optimal mechanical environment of the healing bone fracture/osteotomy. Int Orthop 2012;36:689-95.

12. DiStasio AJ, Jaggears FR, DePasquale LV, Frassica FJ, Turen $\mathrm{CH}$. Protected early motion versus cast immobilization in postoperative management of ankle fractures. Contemp Orthop 1994;29:273-7.

13. van Lieshout R, Pisters MF, Vanwanseele B, de Bie RA, Wouters EJ, Stukstette MJ. Biofeedback in partial weight bearing: usability of two different devices from a patient's and physical therapist's perspective. PLoS One 2016;11:e0165199.

14. Nambiar M, West LR, Bingham R. AO Surgery Reference: a comprehensive guide for management of fractures. Br J Sports Med 2017;51:545-6.

15. Yuk GC. Pressure on sacrum and buttock according to tilt table inclination. J Korean Phys Ther 2013;25:71-5.

16. Kim JS, Kang SY, Kim JK. Weight bearing study using digital scales in hemiplegic patients. J Korean Acad Rehabil Med 2000;24:1055-60.

17. Foo J, Paterson K, Williams G, Clark R. Low-cost evaluation and real-time feedback of static and dynamic weight bearing asymmetry in patients undergoing inpatient physiotherapy rehabilitation for neurological conditions. J Neuroeng Rehabil 2013;10:74. 